\title{
CANADIAN CIVIL ENGINEERING AND SUSTAINABLE DEVELOPMENT COMPETENCE
}

\author{
Wright M; Froese T; Nesbit S \\ Department of Civil Engineering, University of British Columbia, Vancouver, BC, Canada \\ matt.wright@alumni.ubc.ca
}

\section{INTRODUCTION}

Higher education institutions are awarding an increasing number of degrees in engineering every year. The result is an increased supply of new entrants to the engineering labour market. At the same time, the civil engineering profession is in a state of flux as industries are transitioning towards more sustainability-focused operations (ASCE, 2007). Engineering roles have traditionally focused on applied science projects, with little regard for stakeholder involvement, and crossdisciplinary collaboration (Adams, Beltz, Mann, \& Wilson, 2010). This historical baseline has now shifted toward trends that are more closely aligned with sustainable development goals (Kunberger, Burian, Lutey, Morse, \& Sanford Bernhardt, 2011). The engineering profession must now operate within an updated code of ethics, discipline-specific codes and standards, and policy directives that are derived with sustainable development goals in mind.

The overarching goal of the research study was to examine the existing body of knowledge and capture the civil engineering perspective of sustainable development. The preliminary stage involved identifying technical and non-technical sustainability practitioner roles with particular attention to a Canadian work setting. This included government labour projects and labour market reports specific to green industries and careers, as well as trends in existing engineering industries. For the purposes of the study, any role that required an engineering degree and included the terms "green", "triple bottom line" or "sustainability" was considered. Initial findings were then refined to exclude industries that did not employ civil engineers. Defining sustainable development for civil engineers could then be applied to the identification of sustainable development competence.

\section{METHODS}

The selection of a research methodology is largely guided by the type of questions being researched (Creswell, 2014). Figure 1 is an illustration of the research design with a focus on research questions. The exploratory sequential mixed method design shown below begins "with a primary qualitative phase, then the findings are validated or otherwise informed by quantitative results" (Borrego et al., 2009, p. 59). Exploratory sequential mixed method design is also beneficial for creating a robust survey instrument. This aligns with the two-pronged approach of the research study (i.e. qualitative and quantitative results), and creates a flow for exploring sustainable development from multiple perspectives. The combined use of both interviews and an industry survey has been used to qualify and quantify industry expectations in past research studies (Hanning et al., 2012).

Semi-structured interviews were used to gather an understanding of sustainable development from the perspective of the civil engineering community. The interviewees were asked open-ended questions regarding engineering practice, sustainable development in their industry sector, and attributes that are relevant for engineering competence. Probing questions were also used to enhance the prepared interview manuscript in an attempt to develop a refined list of competency items for the final survey instrument. The interview participants also provided commentary on their interpretation of terms, depth of content and overall survey coverage according to procedures in the literature. Transcripts were coded according to major and minor themes that emerged from the interviews. Themes were referenced against the existing survey questions, and additional items were added to form the industry survey.

Following on from the qualitative semi-structured interviews, an industry survey was chosen as the quantitative research method. Several engineering education authors have used industry surveys for competency research studies. The final survey closely resembled the International Society of Sustainability Professionals study (Willard et al., 2010) with a few modifications for the engineering audience. The survey was refined according to development procedures outlined by Fowler (2009). The final Web-based survey instrument was hosted on FluidSurveys, an online survey administration website. The survey was available from November to December 2013 for participants.

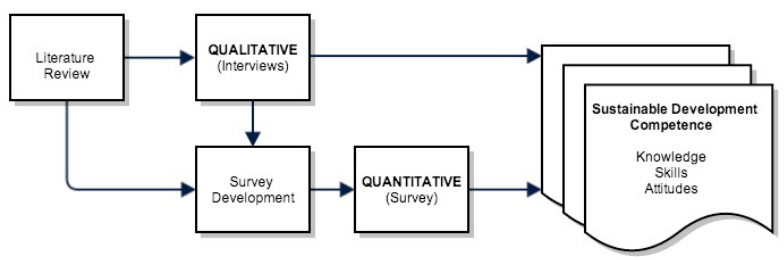

Figure 1: Exploratory sequential mixed methods research design

\section{RESULTS}

Several themes emerged from the semi-structured interviews, including engineering competency, disciplinarity, perceptions of sustainable development, and the engineering profession (current and future). Participants broadly summarized sustainable development as the use of reductionist and innovative design strategies to lessen the impact of engineering projects and activities. These strategies are informed by professional and regulatory mandates, and involve the application of technical engineering knowledge, systems thinking approaches and interdisciplinary teamwork. Figure 2 represents a combination of the semi-structured interview results with the highest ranking knowledge, skills and attitudes identified in the industry survey.

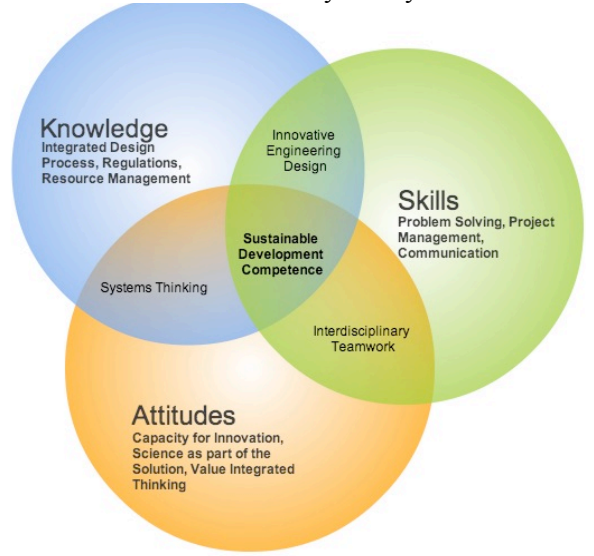

Figure 2: Proposed sustainable development competence

\section{DISCUSSION}

Canadian civil engineering is undergoing a significant transformation as new engineering roles are being created. There are internal and external pressures to change the way engineers practice. Results from both the semi-structured interviews and the industry survey point to disciplinary knowledge and skills that are not being reinforced in the current civil engineering curriculum. There is a need to identify the necessary knowledge, skills and attitudes that are required of employers to accurately train civil engineering undergraduates.

\section{REFERENCES}

Adams, R. S., Beltz, N., Mann, L., \& Wilson, D. IJEE, 26(2)

ASCE. The Vision for Civil Engineering in 2025. ASCE.2007

Borrego, M., Douglas, E. P., \& Amelink, C. T. (2009). JEE 2009: 98(1)

Creswell, J. W. (2014). Research design: qualitative, quantitative, and mixed methods approaches.

Hanning, A., Abelsson, A. P., Lundqvist, U., \& Svanström, M. IJEE 2012: 13(3)

Jarvis, S. E., \& Barberena, L. Encyclopedia of Survey Research Methods. 2008

Kunberger, T., Burian, S., Lutey, W., Morse, A., \& Sanford Bernhardt, K. ASEE 2011.

Willard, M., Wiedmeyer, C., Warren Flint, R., Weedon, J. S., Woodward, R., Feldman, I., \& Edwards, M. (2010). The sustainability professional: 2010 competency survey report. Environmental Quality Management, 20(1), 49-83. 